\title{
Perbaikan Keselamatan Konstruksi Dengan Alat Decking Fall Protection Pada Proyek Pembangunan Gedung Apartemen PT Pertamina
}

\author{
Sulardi \\ Prodi Teknik Sipil Universitas Tridharma Balikpapan \\ e-mail: sulardikm61@yahoo.com
}

\begin{abstract}
Problems faced is the anxiety and sense of concern from the community of road users struck by ballast counter weight ballast when tower crane maneuver position trolley working jib and concrete ballast counter jib tower crane pass over the highway area so that road users stop and cause congestion.This research is the success story of innovation of safety improvement Construction with the manufacture and installation of concrete decking fall protection to prevent fall of ballast counter weght concrete. Concrete decking counter weight using roundbar steel material specification and 1 inch diameter wire strand rope formed as a ballast counter weight weight ballast protector [4]. The results of this innovative implementation of the innovation can significantly improve the safety of ballast counter weight concrete. Concrete decking has a load-bearing strength of up to 186.78 tons vs a weight of 24 tons weight ballast counter weight. With this innovation, Pertamina's apartment construction project is running smoothly and avoiding public complaints. Innovation of concrete decking ballast counter weight decking has been replicated for similar work in Pertamina Cilacap, Pertamina refinery development project of Balikpapan, Balongan and Cilacap and has been used by PT. PP on a 24-storey apartment development project in Surabaya.
\end{abstract}

Keywords: Decking ballast counter weight, trolley working jib, Safety Construction.

\begin{abstract}
Abstrak
Permasalahan yang dihadapi adalah adanya kecemasan dan rasa kekawatiran dari masyarakat pengguna jalan akan kemungkinan tertimpa beton ballast counter weight pada saat tower crane melakukan manuver posisi trolley working jib dan beton ballast counter jib tower crane melintas diatas kawasan jalan raya sehingga pengguna jalan berhenti dan menimbulkan kemacetan. Penelitian ini adalah ini success story inovasi perbaikan keselamatan konstruksi dengan membuat dan memasang beton decking fall protection untuk mencegah jatuhnya beton ballast counter weght. Beton decking counter weight menggunakan spesifikasi material baja roundbar berdiamater 1 inch dan wire type strand rope diameter 1 inch yang dibentuk sebagai basket pelindung beton ballast counter weight [4]. Hasil implementasi inovasi ini terbuksi dapat meningkatkan keselamatan beton ballast counter weight secara signifikan. Beton decking memiliki kekuatan menahan beban hingga 186.78 tons vs berat beton ballast counter weight 24 ton. Dengan inovasi ini proyek konnstruksi pembangunan apartemen Pertamina berjalan lancar dan terhindar dari complain masyarakat. Inovasi penggunaan decking beton ballast counter weight telah direplikasi untuk pekerjaan sejenis di Pertamina Cilacap, proyek pengembangan kilang Pertamina Balikpapan, Balongan dan Cilacap serta telah digunakan oleh PT. PP pada proyek pembangunan apartemen 24 lantai di Surabaya.
\end{abstract}

Kata Kunci : Decking ballast counter weight, trolley working jib, keselamatan Konstruksi.

\section{Pendahuluan}

\subsection{Latar Belakang Masalah}

Proyek pengembangan kilang PT. Pertamina RU V Balikpapan dimulai dengan pembangunan apartemen yang akan diperuntukan bagi para pekerja yang rumahnya terkena dampak pengembangan kilang (RDMP). Gedung apartemen
Pertamina untuk tahap pertama dibangun dikawasan bekas komplek perumahan pekerja Pertamina Dahor dengan ketinggian toping roof setinggi 98 meter diatas permukaan tanah dan okupansinya berbatasan langsung dengan kawasan pemukiman masyarakat Dahor, kantor BNI 46, Jalan Jend. Suprapto dan berbatasan dengan Hotel Blue 
Sky.Pembangunan gedung apartemen ini menggunakan alat angkat tower crane (TC) dengan ketinggian riser boom 118 meter diatas permukaan tanah, jangkauan working jib arm 60 meter dan machinery arm sepanjang 15 meter. Untuk keseimbangan operasi pengangkatan tower crane dilengkapi dengan block beton penyeimbang (ballast counter jib) seberat 24 ton yang dipasang pada machiney arm. Keberadaan Tower crane sangat penting mendukung kelancaran transportasi material dan peralatan untuk pembangunan apartemen. Dengan kondisi lahan yang terbatas, pada saat melakukan manuver swing (berputar) posisi trolley working jib dan ballast counter jib bisa berada diatas kawasan jalan raya yang padat lalulintas.

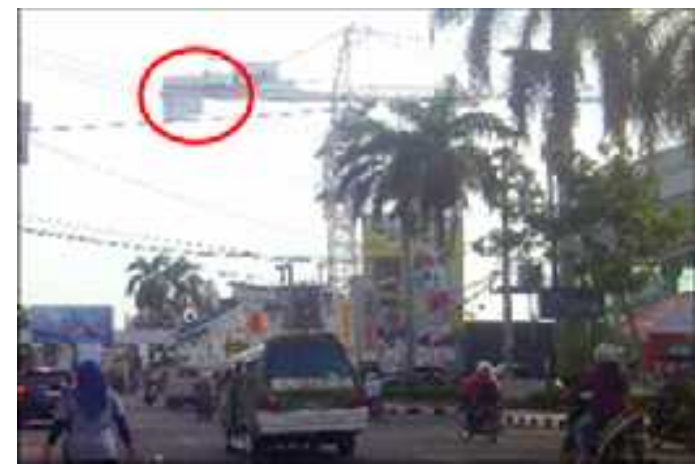

Gambar 1. Ballast counter jib diatas Jalan

Permasalahannya adalah adanya rasa cemas dan rasa kekawatiran dari masyarakat pengguna jalan yang berhenti pada saat beton ballast counter jib melintas diatas jalan karena kawatir tertimpa beton ballast counter jib yang terjatuh [4]. Masih terkait dengan melintasnya lengan ballast counter jib dan working jib tower crane yakni terjadinya kemacetan jalan akibat pengguna alan yang sengaja berhenti menonton maneuver dan berputarnya tower crane.

Telah ada upaya dari pengelola proyek apartemen untuk memberikan penyuluhan kepada masyarakat sekitar tentang keselamatan operasi tower crane dan telah disiapkannya petugas keamanan proyek bekerja sama dengan Dinas Perhubungan Kota
Balikpapan dan Kepolisian untuk mencegah kemacetan lalulintas di Jalan Jenderal Suprapto. Namun upaya pencegahan ini juga tidak efektif karena masih adanya pengguna Jalan yang berhenti pada saat lengan ballast counter jib dan working jib tower crane melintang diatas jalan karena kekawatiran perancam keselamatannya.

Untuk itu diperlukan upaya perbaikan lebih lanjut guna mengatasi permasalahan agar tidak ada dampak lebih lanjut dengan memasang pelindung jatuhnya beton ballast counter jib dan melakukan sosialisasi kepada masyarakat pemakai Jalan bahwa beton ballast counter jib telah diproteksi dengan alat pengaman jatuh (decking fall protection) [4].

\subsection{Tujuan Penelitian}

1. Memberikan gambaran tentang spesifikasi, bentuk, dimensi dan konfigurasi alat decking fall protection untuk beton ballast counter jib

2. Memberikan gambaran tentang cara pembuatan dan pemasangan dan cara kerja decking fall protection terhadap beton ballast counter jib

3. Memberikan gambaran manfaat hasil inovasi pembuatan dan pemasangan alat decking fall protection.

\section{Tinjauan Pustaka}

\subsection{Tower Crane}

Tower Crane (TC) adalah sebuah alat berat bangunan yang digunakan untuk mengangkat material dan peralatan kerja yang umumya tidak dapat diangkat oleh manusia, secara vertikal ataupun horisontal ke tempat yang lebih tinggi dengan ruang gerak yang terbatas [1]. Pada saat ini tower crane banyak digunakan untuk pembangunan gedung bertingkat tinggi seperti pembangunan hotel, apartement, mall, hipermarket dan jenis bangunan tinggi lain yang sejenisnya, Pembangunan gedung-gedung bertingkat banyak menggunakan alat ini dan terbukti sangat efektif karena dapat mempersingkat dan menghemat waktu pelaksanaan pekerjaan untuk sebuah proyek pembangunan, karena 
material dapat terangkat ke lokasi pemasangan dengan lebih mudah dan cepat.

Komponen utama tower crane meliputi jib, yaitu sebuah lengan panjang yang dapat berputar 360 derajat, secara horizontal. Sebuah ruang operator (operator cab) yang berfungsi sebagai tempat pengendali dan pengontol operasi tower crane. Tiang menara (tower mast) yaitu bagian vertikal tower crane sebagai tiang crane, dimana dibagian tengah (dalam) frame tower mast terdapat tangga untuk tempat naik operator. Pemberat penyeimbang (ballast counter weight) yang berfungsi untuk menyeimbangkan lengan crane (jib) ketika mengangkat beban dan pondasi yang berfungsi sebagai bantalan, penyeimbang dan penyangga tower mast dari tower crane agar tower crane tidak roboh [1].

Pondasi tower sebagai counter weight berupa kaki-kaki pelat baja dengan kedudukan tetap yang dibenamkan kedalam beton dengan bentuk dan dimensi tertentu dengan berat yang cukup sehingga dapat menjami keseimbangan dan keselamatan tower mast pada saat dipergunakan untuk pengangkatan beban. Tower mast yang sering dibuat adalah dengan riser tower crane berupa struktur rangka baja (steel frame) yang dikonstruksi dengan dimensi dan bentuk sedemikian rupa sehingga dapat menjamin kestabilan operasi tower crane, dimana tower mast dapat dinaik-turunkan sesuai kebutuhan dengan metode hydraulic jack up.Counter jib adalah lengan penyeimbang beban yang diangkat oleh crane runway, dimana penyeimbang bebannya adalah beton ballast counter weight. Crane runway adalah lengan pengangkat beban dimana terdapat trolley, trolley pulley, hoisting rope, hositing block dan hook.

\subsection{Kerangka Pemikiran}

Material ballast counter weight terbuat dari beton yang dicetak sebgai block-block beton dengan bentuk sedemikian rupa dan dipasang sebagai ballast counter jib dengan 2 buah pin penggantung roundbar baja berdiameter 2,5 inch dan dipasang locking agar tidak terlepas dari kedudukannya.
Potensi pecah dan terjatuhnya beton ballast counter dapat terjadi pada saat block beton saling bergesek dan berbenturan secara berulang-ulang pada saat tower crane dioperasikan. Untuk itu perlu disiapkan alat pengaman pelindung jatuhnya beton ballast counter weight yang dapat mencegeh saling bergesekan, saling berbenturan dan mampu menahan beban ballast counter weight yang selanjutnya disebut sebagai alat decking fall protection [4].

Spesifikasi alat decking fall protection adalah terbuat dari tulangan baja roundbar diameter 1 inch dan diperkuat dengan wire rope berdiamater 1 inch yang didisain dengan bentuk sedemikian rupa sehingga membentuk keranjang pelindung yang dipasang menutup seluruh beton ballast counter weight dan diikatkan pada steel frame counter jib. Target perbaikan adalah membuat dan memasang decking fall protection dengan kapasitas $>72$ ton untuk menjamin keselamatan beton decking ballast counter weight agar tidak terjatuh.

\section{Metode Penelitian}

\subsection{Urgensi Penelitian}

Penelitian ini adalah penelitian terapan dengan pendekatan studi kasus, yakni implementasi decking fall protection dalam rangka mengatasi masalah keselamatan konstruksi penggunaan alat tower crane untuk pekerjaan pembangunan Apartemen Pertaminayang menggunakan pada tower crane setinggi 116 meter yang dipergunakan pada pekerjaan proyek konstruksi bangunan gedung apartemen Pertamina. Dengan penggunaan alat decking fall protection ini pekerjaan proyek pembangunan apartemen Pertamina berjalan lancar dan terhindar dari gangguan phak-pihak luar yang merasa keselamatannya terancam pada saat melintas dilingkungan pekerjaan proyek apartemen.

\subsection{Metode Penelitian}

\section{Bahan digunakan}

Bahan-bahan pembuatan decking fall protection adalah : 
a. Roundbar tulangan beton lurus, diamater 1 inch, baja mutu tinggi

b. Tali kawat baja (wire rope) type inti pilinan kawat baja (strand core), diameter 1 inch

c. Shacle clips bentuk U, kapasitas 12 tons

d. Padeyes plate tebal 1,5 inch

2. Peralatan digunakan

a. Mesin potong, gergaji

b. Mesin las listrik

c. Mesin pembengkok roundbar

d. Alat uji tarik wire rope (sling) type strand core rope.

\section{Metode kerja}

a Siapkan roundbar dengan dimensi yang sesuai

b. Siapkan wire rope dengan dimensi yang sesuai, telah uji tarik dan telah diketahui kapasitas putusnya

c. Bentuk roundbar dengan mesin pembengkok

d. Buat padeyes plate dengan bentuk sedemikian rupa sehingga dapat diikatkan dengan baik terhadap shacle clips

e. Anyam sehongga membentuk keranjang roundbar dengan menyesuaikan posisi steel frame counter jib

f. Pasang engsel disisi bawah keranjang roundbar dan pasang padeyes plate disisi atas keranjang roundbar

g. Pastikan bisa dengan mudah dipasang menutup beton beton ballast counter jib

h. Las dengan baik engsel dan padeyes plate terhadap ujung roundbar atas dan bawah

i. Pasang wire rope (seling) mengikuti bentuk roundbar dan ikat pertemuan ujungnyanya dengan clamps

j. Tutup decking fall protection dengan terpal yang telah dibentuk sedemikian rupa

k. Decking fall protection siap digunakan.

\section{Hasil dan Pembahasan}

\subsection{Hasil Penelitian}

\section{Hasil Uji tarik wire rope}

Tujuan uji tarik adalah untuk mengetahui kapasitas mampu layan roundbar dan wire yang akan digunakan sebagai bahan decking fall protection. Pengujian tarik wire rope (sling) dilakukan di PT. Franklin Offshore menggunakan mesin tarik baja tarik tester dengan mesin hidrolik tidur, Merek BJTM, model TM 300, kapasitas tarik 300 tons. Diamater wire rope 1 inch dan panjang benda uji 10 meter dengan metode uji sesuai SNI 0076 : 2008[2][3]. Pengujian tarik hanya dilakukan pada material wire rope karena material utama penahan beban adalah wire, sedangkan roundbar hanyalah sebagai pembentuk keranjang saja.

Hasil uji terhadap 3 benda uji masingmasing putus pada uji tarik 65,8 tons, 67,5 ton dan 62,5 tons atau wire rope akan putus pada saat dibebani dengan beban (rata-rata) 65.26 ton. Dengan demikian wire strand rope diameter 1 inch layak digunakan dan dililitkan sebanyak 3 lilitan pada keranjang decking fall protection dengan safety factor 2.594. Pertemuan kedua ujung wire rope didambung dengan clamp plate diameter 1 inch berbahan dasar stainless steel.

\section{Hasil Implementasi}

Spesifikasi material decking beton ballast fall protection adalah baja roundbar diameter 1 inch, wire rope type stand core diameter 1 inch dengan kapasitas tarik maksimum 62,26 ton dan dipasang dengan 3 lilitan mengikuti konfigurasi steel basket sehingga kapasitas menahan beban secara total 186.78 tons sebagai pelindung beton ballast counter weight dari bahaya terjatuh. Cara pemasangan decking beton ballast counter weght adalah dengan cara mengikatkan shackle clip dan padeyes plate decking pada steel frame counter jib sehingga terpasang dengan kokoh dan stabil. Setelah tidak digunakan decking dilepas kembali dan disimpan untuk digunakan dilain kesempatan.

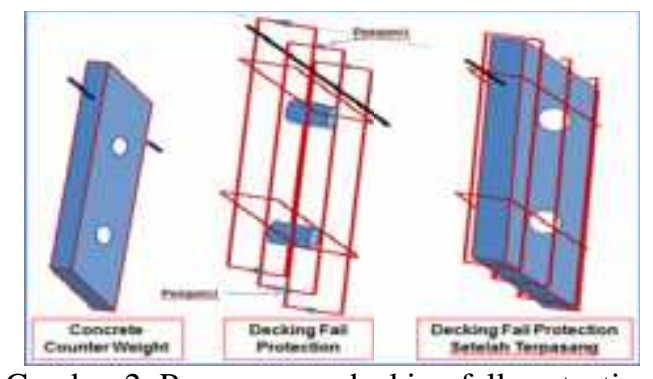

Gambar 2. Pemasangan decking fall protection 
Inplementasi decking beton ballast counter weight dengan bentuk dan konfigurasi pemasangan sebagaimana tersaji pada gambar berikut adalah penerapan alar decking fall protection pada tower crane yang digunakan pada pembangunan apartemen Pertamina RU V Balikpapan setinggi 96 meter dan terbukti dapat mengatasi permasalahan dengan baik seingga pekerjaan pembangunan apartemen dapat diselesaikan dengan lancar dan aman[4].

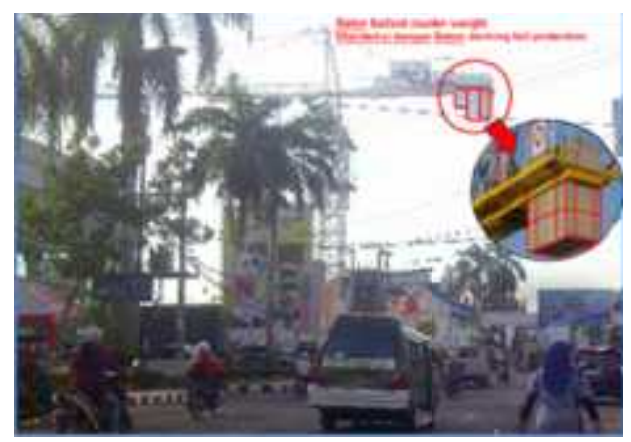

Gambar. 3 Decking fall protection terpasang

Telah selesai dilakukan pembuatan dan pemasangan decking beton ballast counter weight dibuat dengan spesifikasi material frame round bar berukuran 1 inch dan diperkuat dengan wire rope type strand core berdiameter 1 inch sehingga memiliki kapasitas total menahan beban secara signifikan sehingga dapat memberikan jaminan keselamatan jika ada kemungkinan terjadi kegagalan pada beton ballast counter weight seberat 24 tons tidak membahayakan lingkungan disekitarnya. Kekuatan mampu dukung beban alat decking fall protection adalah 186,78 tons atau $776 \%$ kali berat beton ballast counter weight sehingga jika terjadi kegagalan maka beton ballast counter weight tidak akan terjatuh dan tidak akan mengakibatkan unstabil pada tower crane[4].

\subsection{Pembahasan}

Alat decking fall protection untuk beton ballast counter jib dan merupakan inovasi baru yang dari hasil peneliusuran referensi baru pertama kali digunakan dilikungnan Pertamina dan kota Balikpapan. Pemasangan alat decking fall protection terbukti dapat memperbaiki keselamatan konstruksi tower crane dan meyakinkan kepada masyarakat pemakai jalan bahwa keselamatannya terjamin, lalulintas tetap berjalan dengan lancar dan tertib meskipun beton ballast counter weight seberat 24 ton melintas diatas jalan.

Decking beton ballast counter weight dibuat dengan material frame roundbar berukuran 1 inch dan diperkuat dengan wire rope type strand core berdiameter 1 inch dengan total kapasitas menahan beban seberat 186.78 ton dapat memberikan jaminan keselamatan jika beton ballast counter weight seberat gagal tidak membahayakan lingkungan disekitarnya. Target perbaikan membuat dan memasang beton decking dengan kapasitas menahan beban (72 ton) vs 186.78 ton, tercapai dan bahkan terlampaui hingga 300\%[4].

Hasil penelitian dari aspek panca mutu meliputi hasil penelitian dari aspek quality meliputi (1) beton ballast counter weight telah diproteksi dengan alat decking fall protection dan dilakukan pemeriksaan secara berkala untuk memastikan kondisinya aman (2) alat decking fall protection untuk beton ballast counter weight dibuat dengan spesifikasi material roundbar dan wire strand core rope yang memiliki kapasitas menahan beban 186,78 tons. Hasil penelitian dari aspek cost meliputi proyek berjalan lancar, terhindar dari potensi kerugian senilai. Rp.20 M. Hasil penelitian delivery meliputi tower Crane berfungsi dengan baik dan aman, proyek pembangunan apartemen terhindar dari penghentian akibat complain masyarakat selama. 2 minggu. Hasil penelitian dari aspek safety adalah (1) tersedianya alat decking fall protection untuk mencegah jatuhnya beton ballast counter weight yang memiliki kapasitas mampu menahan beban hingga 776\%[4] (2) beton ballast counter weight terhindari dari jatuh [4](3) siklus kegiatan proyek tetap lancar, transportasi sumber daya material, peralatan dan tenaga kerja kontinyu. Dan hasil penelitian dari aspek moral adalah (1) inovasi alat decking fall 
protection dapat memberikan respon good image terhadap implementasi keselamatan kerja kepada Pertamina (2) pekerja dan masyarakat konfiden, manajemen proyek telah melakukan upaya nyata memberikan jaminan keamanan operasi crane.

\section{Penutup}

\subsection{Kesimpulan}

a. Inovasi pembuatan dan pemasangan alat decking fall protection untuk beton ballast counter jib tower crane proyek pembangunan apartemen Pertamina dengan spesifikasi material roundbar diameter 1 inch dan wire type strand rope diameter 1 inch terbukti dapat memperbaiki keselamatan Konstruksi dan dapat mengatasi masalah kekawatiran masyarakat pengguna jalan dan potensi bahaya terjatuhnya beton ballast counter jib

b. Atas keberhasilan hasil inovasi pembuatan dan pemasangan alat decking fall protection pada proyek pembangunan apartemen Pertamina RU V, pada saat ini peralatan sejenis telah digunakan pada proyek pembangunan apartemen Pertamina RU IV Cilacap dan pada proyek pengembangan kilang Pertamina

c. Inovasi pembuatan dan pemasangan alat decking fall protection dapat meningkatkan kepercayaan masyarakat terhadap penerapan safety good image kepada Pertamina.

\subsection{Saran-saran}

a. Hasil inovasi ini dapat meningkatkan aspek safety dan kepercayaan masyarakat terhadap penanganan bahaya pekerjaan Konstruksi, dapat direplikasi pada proyekproyek pekerjaan Konstruksi sejenis dilingkungan unit Pertamina yang lain, di lingkungan industri migas dan dilingkungan Pekerjaan umum

b. Hasil inovasi decking fall protection ini dapat dikembangkan dengan spesifikasi, bentuk, dimensi dan konfigurasi yang lebih baik dengan peruntukan yang lebih bervariasi c. Hasil inovasi dapat menjadi referensi dalam peningkatan keselamatan Konstruksi dan keselamatan alat angkat tower crane.

\subsection{Ucapan Terimakasih}

Dengan telah selesainya penulisan hasil penelitian dalan rangkasucces story inovasi alat decking fall protection ini Penulis mengucapkan terimakasih kepada Manajemen PT. Pembangunan Perumahan (PT.PP) yang telah mengimplementasikan inovasi ini pada tower crane proyek pembangunan apartemen Pertamina. Terimakasih juga kepada manajemen PT. Arham Reedha yang telah memfasilitasi pengujian tarik tali baja (wire strand rope) di PT. Franklin Offshore Indonesia.

\section{Daftar Pustaka}

[1]. ASME B30.3, 2009, Tower Cranes Safety Standard for Cableways, Cranes, Derricks, Hoists, Hooks, Jacks, and Slings, The American Society of Mechanical Engineers Three Park Avenue, New York, NY 100165990

[2]. Peraturan Menteri Perindustrian RI No. 45/M-IND/PER/4/2011,Tentang Pemberla kuan Standar Nasional Indonesia Tali Kawat Baja dan Tali Kawat Baja untuk Minyak dan Gas Bumi Secara Wajib

[3]. SNI 0727 : 2008, 2012, Tali Kawat Baja untuk Minyak dan Gas Bumi, Badan Standar Nasional Indonesia (BSNI)

[4]. Sulardi, 2016, Mencegah Potensi Bahaya Kegagalan Beton Counter Weight Pada Tower Crane Proyek Pembangunan Apartemen Pertamina, PT. Pertamina Corporate, Jakarta; http://ptmkpwab81. Pertamina.com/komet/searchResult.aspx?, Kodefikasi. 160510002. 